Thomas Nyffeler • Charles Pierrot-Deseilligny •

Tobias Pflugshaupt • Roman von Wartburg •

Christian W. Hess · René M. Müri

\title{
Information processing in long delay memory-guided saccades: further insights from TMS
}

Received: 7 April 2003 / Accepted: 15 July 2003 / Published online: 25 October 2003

(C) Springer-Verlag 2003

\begin{abstract}
The performance of memory-guided saccades with two different delays ( $3 \mathrm{~s}$ and $30 \mathrm{~s}$ of memorisation) was studied in eight subjects. Single pulse transcranial magnetic stimulation (TMS) was applied simultaneously over the left and right dorsolateral prefrontal cortex (DLPFC) $1 \mathrm{~s}$ after target presentation. In both delays, stimulation significantly increased the percentage of error in amplitude of memory-guided saccades. Furthermore, the interfering effect of TMS was significantly higher in the short delay compared to that of the long delay paradigm. The results are discussed in the context of a mixed model of spatial working memory control including two components: First, serial information processing with a predominant role of the DLPFC during the early period of memorisation and, second, parallel information processing, which is independent from the DLPFC, operating during longer delays.
\end{abstract}

Keywords Human - Visuospatial working memory · Transcranial magnetic stimulation - Dorsolateral prefrontal cortex

\section{Introduction}

In humans, a large cortical network is involved in the control of spatial memory, including the posterior parietal cortex (PPC) (Heide et al. 2001; Pierrot-Deseilligny et al.

\footnotetext{
T. Nyffeler · T. Pflugshaupt · R. von Wartburg $\cdot$ C. W. Hess R. M. Müri $(\bowtie)$

Perception and Eye Movement Laboratory, Department of Neurology, University Hospital, University of Bern,

Freiburgstrasse 10,

3010 Bern, Switzerland

e-mail: rene.mueri@insel.ch

Tel.: +41-31-6322111

Fax: +41-31-6329679

C. Pierrot-Deseilligny

INSERM 289 et Service de Neurologie 1 (AP-HP), Hôpital de

la Salpêtrière,

47 Bd. de l' Hôpital,

75651 Paris cedex 13, France
}

1991; Sweeney et al. 1996), the dorsolateral prefrontal cortex (DLPFC) (Leung et al. 2002; O'Sullivan et al. 1995; Pierrot-Deseilligny et al. 1991), the frontal eye field (FEF) (Gaymard et al. 1999; Rivaud et al. 1994), and the medial temporal lobe (MTL) (see for a review PierrotDeseilligny et al. 2002; Ploner et al. 1999). Transcranial magnetic stimulation (TMS) studies suggest that the initial stage of visuospatial integration, during some $300 \mathrm{~ms}$ following the target, is under control of the PPC (Müri et al. 1996) and that subsequent memorisation is first controlled by the DLPFC (Müri et al. 1996, 2000). Furthermore, lesion studies in patients suggest that after $20 \mathrm{~s}$ of memorisation or longer, the MTL starts contributing to spatial working memory (Ploner et al. 1999). Taken together, these studies point to a temporal hierarchy in oculomotor control. However, it is not clear whether the MTL receives visuospatial signals directly from the PPC or indirectly via the DLPFC. The latter possibility would argue for an entirely serial, the former for an additional parallel, information processing component.

In order to test the two hypotheses, we recently studied the influence of early TMS on memory-guided saccades with two different saccade delays of 3 and $30 \mathrm{~s}$ of memorisation (Nyffeler et al. 2002). In the memoryguided saccade task, the subject has to memorise the spatial location of a target. After a delay he has to perform a saccade towards the memorised location. Transient inactivation of the right DLPFC by double pulse TMS early after appearance of the target significantly impaired the accuracy of contralateral memory-guided saccades and thus revealed a functional dominance of DLPFC during early memorisation. Since the DLPFC stimulation disordered the saccades irrespective of the duration of the preceding delay, a serial information processing is suggested. However, evidence for an additional parallel information processing component was also found: the degrading effect of TMS on the saccades was significantly greater with the short saccade delay, suggesting that during longer memorisation periods the MTL got access to additional spatial information from other structures 
enabling a partial rectification of the stimulation- induced saccade inaccuracy. Theoretically, additional information to the MTL could come from the PPC directly. However, it is known from lesion studies and electrophysiological studies that the DLPFC contributes to the control of contralateral and ipsilateral memory-guided saccades (Müri et al. 1996, 2000; Nyffeler et al. 2002; PierrotDeseilligny et al. 1991). Therefore, additional spatial information could also come to the MTL via the DLPFC of the other hemisphere. In fact, both types of anatomic connections exist between these regions (Ding et al. 2000; Goldman-Rakic and Schwartz 1982, 1984; Schwartz and Goldman-Rakic 1982; Selemon and Goldman-Rakic 1988; Seltzer and Pandya 1984; Seltzer and Van Hoesen 1979).

Therefore, the aim of the present study was to determine the effect of bilateral simultaneous inactivation of the DLPFC by TMS. Only by inhibiting both DLPFC simultaneously could the model of a serial organisation be corroborated or contradicted. Hence, if stimulusinduced inaccuracy of early bilateral stimulation is similar under both delay conditions, serial processing is likely with an information transfer through both DLPFC. If the degrading effect of early bilateral DLPFC stimulation on saccade accuracy is again significantly greater in short than in long delay saccades, an additional information transfer to the MTL, probably from the PPC, has to be assumed, indicating a parallel processing component for long memorisation periods.

\section{Materials and methods}

Eight healthy subjects (one woman and seven men) were examined: one of them was left handed. Their mean age was 32 years (range: 30-43 years). All volunteers were naïve to the purposes of the study and had normal or corrected to normal visual acuity. The study was consistent with the Declaration of Helsinki and approved by the ethics committee of the University of Bern. All subjects gave informed consent prior to participation.

Saccade paradigm and experimental design

We used a paradigm of memory-guided saccades with two different delays ( 3 or $30 \mathrm{~s}$ ). The subjects, initially fixating a central point, were instructed to memorise the location of a horizontally presented lateral target, which had an unpredictable direction and amplitude, ranging from 8 to 16 degrees. The target was shown for $80 \mathrm{~ms}$. After the memorisation delay of 3 or $30 \mathrm{~s}$, the central fixation point extinguished. This was the go signal for the subject to perform a saccade towards the memorised target location. The previously flashed target was shown again after another $2 \mathrm{~s}$ and the subject had to make a corrective saccade if necessary. The next trial began again at the central fixation point. Subjects were seated in total darkness and the head was stabilized with a chin rest. We measured eye movements bitemporally by means of DC electro-oculography (EOG) (sampling frequency $1,000 \mathrm{~Hz}$, bandwidth $0-100 \mathrm{~Hz}$ ). The digitised signal was stored on the computer for offline analysis. TMS was applied using two figure-of-eight coils (with a total diameter of $15 \mathrm{~cm}$ ) localised over the left and the right DLPFC. A monophasic MagStim BiStim stimulator (MagStim Co., Wales, UK) was used. The DLPFC was localised according to the previously described procedures (Müri et al. 2001; Pascual-Leone et al. 1996, 2000). In brief, after localising the motor hand area by motor threshold stimulation, the coil was moved on average $5 \mathrm{~cm}$ anteriorly. Subjects reported no hand muscle contractions at this position. Stimulus intensity was set at $60 \%$ of the stimulator output, which was $110-130 \%$ of the relaxed individual motor threshold of the small hand muscles. TMS pulses with identical strengths were applied simultaneously. In both paradigms, TMS was applied $1 \mathrm{~s}$ after the flashed target. For each condition (stimulation/no stimulation) and each direction (leftward/rightward saccades), at least 20 trials were acquired for both short and long delays. The trials were presented in blocks of five saccades under the same delay condition. Subjects were always informed about the paradigm that was to be tested. Subjects were examined in two sessions of approximately $1 \mathrm{~h}$ including pauses. The accuracy of memory-guided saccades was assessed. In order to achieve this, the mean percentage of error in amplitude (PEA) was calculated according to the following formula:

$\frac{\mid \text { saccade amplitude }- \text { target amplitude } \mid}{\text { target amplitude }} \times 100 \%$

Non-parametric statistical analysis (i.e. Wilcoxon test) was performed. Since it is known that without stimulation the PEA of memory-guided saccades increases with increasing delay, a second parameter was calculated to eliminate the influence of the delay per se. For each subject, the percentage of increase in the PEA was calculated for each delay according to the following formula:

$\left(\frac{P E A(\text { stim })}{P E A(\text { nostim })} * 100 \%\right)-100 \%$

Therefore, a value of $0 \%$ means no TMS effect on PEA.

\section{Results}

In a first step, a statistical comparison of the PEA for rightward and leftward memory-guided saccades was done. There was no statistically significant difference $(P>0.5)$. Therefore, data from right- and leftward memoryguided saccades were pooled for further analyses. These results are presented in Fig. 1a: single pulse TMS simultaneously applied over both DLPFC significantly increased the PEA in the short saccade delay paradigm (median PEA: 11\% without stimulation; 25\% with TMS; $P<0.005)$ as well as in the long saccade delay paradigm (median PEA: 18\% without stimulation; 24\% with TMS; $P=0.02$ ), compared to the PEA without stimulation.

The percentage of increase in the PEA is shown in Fig. 1b). TMS had a significantly greater effect $(P=0.003)$ in the short (median increase of $84 \%$, interquartile range: $109 \%$ ) as opposed to the long delay paradigm (median increase of $26 \%$, interquartile range: $82 \%$ ).

\section{Discussion}

In this study, we used simultaneous bilateral TMS to interfere with bihemispheric DLPFC functioning during memory-guided saccades in order to separate up serial and parallel components of working memory control. One finding was that stimulation $1 \mathrm{~s}$ after target presentation significantly degraded the accuracy of memory-guided saccades, irrespective of saccade direction. Furthermore, saccade accuracy was impaired in both the short as well as 


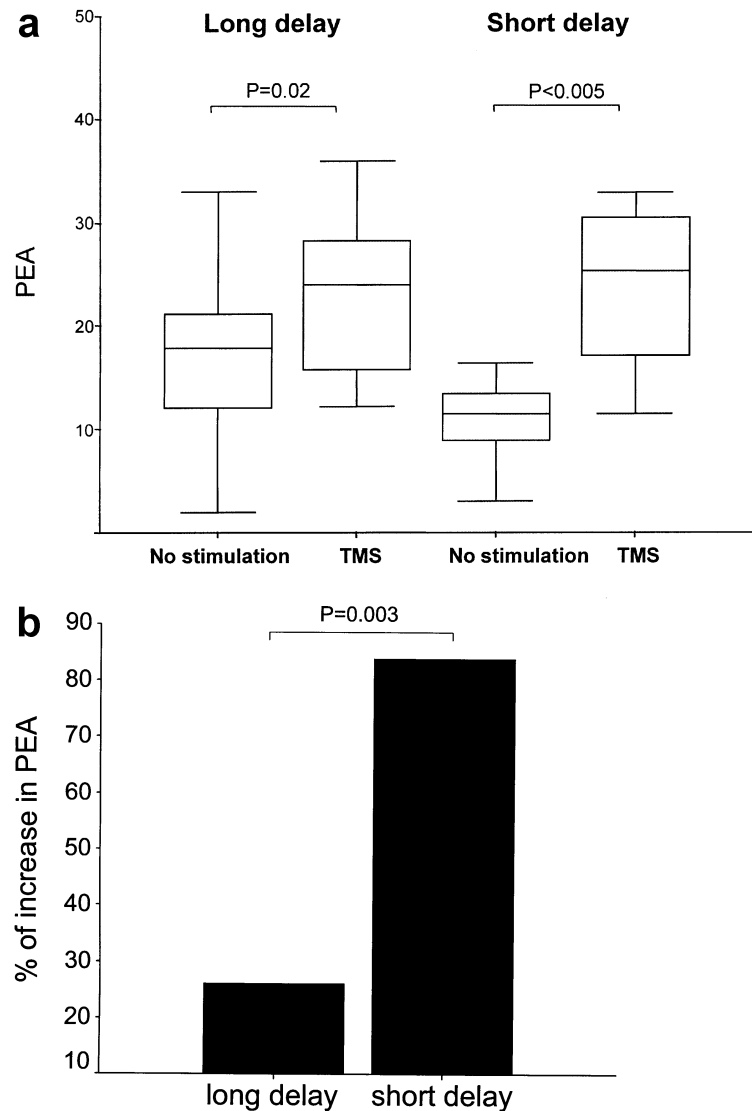

Fig. 1 a Effect of TMS on the PEA in the two different paradigms. The figure shows summary plots based on the median, quartiles, and range. The box represents the interquartile range. TMS had a significant effect on the PEA both in the short $(P<0.005)$ and long delay paradigm $(P=0.02)$. b Percentage of increase in the PEA. The effect of TMS was significantly $(P=0.003)$ greater in the short (median increase of $84 \%$ ) than in the long delay paradigm (median increase of $26 \%$ )

the long saccade delay paradigm, indicating that TMS interference with DLPFC functioning affects the spatial saccade memorization in a critical phase. These findings support the model of a serial processing of working memory.

The second, more important finding was that the degree of the degrading effect of bilateral DLPFC stimulation on the accuracy of memory-guided saccades was delay dependent, being more pronounced when saccades were executed after a short memorisation period. This means that during the long delay, memory processing must have access to additional information. Such a delay-dependent TMS effect was also found for contralateral memoryguided saccades after unilateral stimulation (Nyffeler et al. 2002). However, it was not clear whether additional memory processing was directed from the PPC to the MTL (i.e. parallel processing) or transferred from the DLPFC of the other hemisphere (i.e. serial processing). Now, by inactivating both DLPFC, such an interhemispheric transfer of information becomes unlikely. The current findings allow corroboration of the model of an additional parallel processing in long delays. Hence, for long delays, working memory relies on visuospatial information that has been initially directed from the PPC to the MTL (Ding et al. 2000; Seltzer and Pandya 1984; Seltzer and Van Hoesen 1979) and not on information transferred from the DLPFC of the other hemisphere.

Taking the results of the present and previous TMS studies together, the findings corroborate the proposed mixed model of spatial working memory (Pierrot-Deseilligny et al. 2002; Ploner et al. 2000): both the DLPFC and MTL receive visuospatial signals that were initially integrated in the PPC during the first $300 \mathrm{~ms}$. The DLPFC is controlling spatial working memory during the first seconds and conveys visuospatial information to the MTL. Finally, the MTL contributes to spatial memory at delays longer than $20 \mathrm{~s}$.

Acknowledgement This study was supported by Swiss National Foundation grant no. 31-59448.99.

\section{References}

Ding SL, Van Hoesen G, Rockland KS (2000) Inferior parietal lobule projections to the presubiculum and neighboring ventromedial temporal cortical areas. J Comp Neurol 425:510-530

Gaymard B, Ploner CJ, Rivaud-Pechoux S, Pierrot-Deseilligny C (1999) The frontal eye field is involved in spatial short-term memory but not in reflexive saccade inhibition. Exp Brain Res 129:288-301

Goldman-Rakic PS, Schwartz ML (1982) Interdigitation of contralateral and ipsilateral columnar projections to frontal association cortex in primates. Science 216:755-757

Goldman-Rakic PS, Selemon LD, Schwartz ML (1984) Dual pathways connecting the dorsolateral prefrontal cortex with the hippocampal formation and parahippocampal cortex in the rhesus monkey. Neuroscience 12:719-743

Heide W, Binkofski F, Seitz RJ, Posse S, Nitschke MF, Freund HJ, Kompf D (2001) Activation of frontoparietal cortices during memorized triple-step sequences of saccadic eye movements: an fMRI study. Eur J Neurosci 13:1177-1189

Leung HC, Gore JC, Goldman-Rakic PS (2002) Sustained mnemonic response in the human middle frontal gyrus during online storage of spatial memoranda. J Cogn Neurosci 14:659671

Müri RM, Vermersch AI, Rivaud S, Gaymard B, Pierrot-Deseilligny C (1996) Effects of single-pulse transcranial magnetic stimulation over the prefrontal and posterior parietal cortices during memory-guided saccades in humans. J Neurophysiol 76:21022106

Müri RM, Gaymard B, Rivaud S, Vermersch A, Hess CW, PierrotDeseilligny C (2000) Hemispheric asymmetry in cortical control of memory-guided saccades. A transcranial magnetic stimulation study. Neuropsychologia 38:1105-1111

Müri RM, Hess CW, Pierrot-Deseilligny C (2001) Eye movements. In: Pascual Leone A, Davy N, Wasserman E (eds) Handbook of magnetic stimulation. Arnold, London, pp 313-322

Nyffeler T, Pierrot-Deseilligny C, Felblinger J, Mosimann UP, Hess CW, Müri RM (2002) Time-dependent hierarchical organization of spatial working memory: a transcranial magnetic stimulation study. Eur J Neurosci 16:1823-1827

O'Sullivan EP, Jenkins IH, Henderson L, Kennard C, Brooks DJ (1995) The functional anatomy of remembered saccades: a PET study. Neuroreport 6:2141-2144 
Pascual-Leone A, Rubio B, Pallardo F, Catala MD (1996) Rapidrate transcranial magnetic stimulation of left dorsolateral prefrontal cortex in drug-resistant depression. Lancet 348:233-237

Pascual-Leone A, Walsh V, Rothwell (2000) Transcranial magnetic stimulation in cognitive neuroscience-virtual lesion, chronometry, and functional connectivity. Curr Opin Neurobiol 10:232-237

Pierrot-Deseilligny C, Rivaud S, Gaymard B, Agid Y (1991) Cortical control of memory-guided saccades in man. Exp Brain Res 83:607-617

Pierrot-Deseilligny C, Müri RM, Rivaud-Pechoux S, Gaymard B, Ploner CJ (2002) Cortical control of spatial memory in humans: the visuooculomotor model. Ann Neurol 52:10-19

Ploner CJ, Gaymard BM, Ehrle N, Rivaud-Pechoux S, Baulac M, Brandt SA, Clemenceau S, Samson S, Pierrot-Deseilligny C (1999) Spatial memory deficits in patients with lesions affecting the medial temporal neocortex. Ann Neurol 45:312319

Ploner CJ, Gaymard B, Rivaud-Pechoux S (2000) Lesions affecting the parahippocampal cortex yield spatial memory deficits in humans. Cereb Cortex 10:1211-1216
Rivaud S, Müri RM, Gaymard B, Vermersch AI, Pierrot-Deseilligny C (1994) Eye movement disorders after frontal eye field lesions in humans. Exp Brain Res 102:110-120

Schwartz ML, Goldman-Rakic PS (1982) Single cortical neurones have axon collaterals to ipsilateral and contralateral cortex in fetal and adult primates. Nature 299:154-155

Selemon LD, Goldman-Rakic PS (1988) Common cortical and subcortical targets of the dorsolateral prefrontal and posterior parietal cortices in the rhesus monkey: evidence for a distributed neural network subserving spatially guided behavior. J Neurosci 8:4049-4068

Seltzer B, Pandya DN (1984) Further observations on parietotemporal connections in the rhesus monkey. Exp Brain Res 55:301-312

Seltzer B, Van Hoesen GW (1979) A direct inferior parietal lobule projection to the presubiculum in the rhesus monkey. Brain Res 179:157-161

Sweeney JA, Mintun MA, Kwee S, Wiseman MB, Brown DL, Rosenberg DR, Carl JR (1996) Positron emission tomography study of voluntary saccadic eye movements and spatial working memory. J Neurophysiol 75:454-468 